\title{
Star-shaped and linear $\pi$-conjugated oligomers consisting of a tetrathienoanthracene core and multiple diketopyrrolopyrrole arms for organic solar cells
}

\author{
Hideaki Komiyama*1,2, Chihaya Adachi ${ }^{1,3}$ and Takuma Yasuda*2
}

Open Access

\author{
Full Research Paper \\ Address: \\ ${ }^{1}$ International Institute for Carbon Neutral Energy Research \\ (WPI-I2CNER), Kyushu University, 744 Motooka, Nishi-ku, Fukuoka \\ 819-0395, Japan, ${ }^{2}$ INAMORI Frontier Research Center (IFRC), \\ Kyushu University and ${ }^{3}$ Center for Organic Photonics and Electronics \\ Research (OPERA), Kyushu University \\ Email: \\ Hideaki Komiyama* - komiyama@ifrc.kyushu-u.ac.jp; \\ Takuma Yasuda* - yasuda@ifrc.kyushu-u.ac.jp \\ * Corresponding author \\ Keywords: \\ bulk heterojunction; diketopyrrolopyrrole; organic solar cells; \\ star-shaped oligomers; tetrathienoanthracene
}

Beilstein J. Org. Chem. 2016, 12, 1459-1466. doi:10.3762/bjoc. 12.142

Received: 18 April 2016

Accepted: 01 July 2016

Published: 14 July 2016

This article is part of the Thematic Series "Organo photovoltaics".

Guest Editor: D. J. Jones

(C) 2016 Komiyama et al.; licensee Beilstein-Institut. License and terms: see end of document.

\begin{abstract}
Solution-processable star-shaped and linear $\pi$-conjugated oligomers consisting of an electron-donating tetrathienoanthracene (TTA) core and electron-accepting diketopyrrolopyrrole (DPP) arms, namely, TTA-DPP4 and TTA-DPP2, were designed and synthesized. Based on density functional theory calculations, the star-shaped TTA-DPP4 has a larger oscillator strength than the linear TTADPP2, and consequently, better photoabsorption property over a wide range of visible wavelengths. The photovoltaic properties of organic solar cells based on TTA-DPP4 and TTA-DPP2 with a fullerene derivative were evaluated by varying the thickness of the bulk heterojunction active layer. As a result of the enhanced visible absorption properties of the star-shaped $\pi$-conjugated structure, better photovoltaic performances were obtained with relatively thin active layers $(40-60 \mathrm{~nm})$.
\end{abstract}

\section{Introduction}

Solution-processable organic semiconductors have been intensively studied as key materials for low-cost, flexible, and largearea optoelectronic devices, including organic solar cells (OSCs) [1-4]. OSCs have drawn much attention as promising next-generation renewable energy sources because abundant sun-light energy can be directly converted into electricity. Recently, the power conversion efficiencies (PCEs) of OSCs based on small molecules with bulk heterojunction (BHJ) archi- tectures have rapidly increased to approximately $10 \%[5]$, approaching those of state-of-the-art polymer-based OSCs [6,7]. To produce high-performance OSCs, the donor materials are required to possess suitable frontier orbital energy levels, high carrier mobility, excellent film-forming ability, and good miscibility with a fullerene derivative as an acceptor. Moreover, strong visible light photoabsorption ability for visible light is vital for the donor materials. 
Star-shaped molecules tethering multiple $\pi$-conjugated arms are capable of harvesting incident light effectively owing to their extended dimensionality, in comparison to their linear analogues. Star-shaped $\pi$-conjugated molecules consisting of hexaperi-hexabenzocoronene [8-14], pyrene [15-17], and triphenylamine [18-23] central cores have been developed as donor materials for BHJ-OSCs. The design of star-shaped $\pi$-conjugated molecules offers possibilities for not only further enhancement of the photoabsorption ability but also for the improvement of molecular packing, solubility, and film-forming ability. However, the impact of star-shaped molecular structures on optoelectronic functionality has not been fully characterized because of the small variation in the central core units researched so far. Herein, we report the design and synthesis of a new star-shaped $\pi$-conjugated oligomer composed of an electron-donating tetrathienoanthracene (TTA) core coupled with multiple electronaccepting diketopyrrolopyrrole (DPP) arms, and its linear ana- logue, TTA-DPP4 and TTA-DPP2 (Figure 1). TTA can be regarded as a promising central core unit for star-shaped $\pi$-conjugated oligomers, and has previously been utilized as a building block of semiconducting polymers for OSCs [24] and organic field-effect transistors [25-27]. To the best of our knowledge, however, there has been no precedent on TTA-based star-shaped and linear $\pi$-conjugated oligomers that can be applied to OSCs.

\section{Results and Discussion Molecular design and synthesis}

To develop star-shaped and linear $\pi$-conjugated oligomers with acceptor-donor-acceptor electronic structures, an electron-donating TTA unit was coupled with electron-accepting diketopyrrolopyrrole (DPP)-based chromophoric units, which are well-known building blocks used in OSCs [28-31]. Such molecular structures facilitate intramolecular charge transfer,

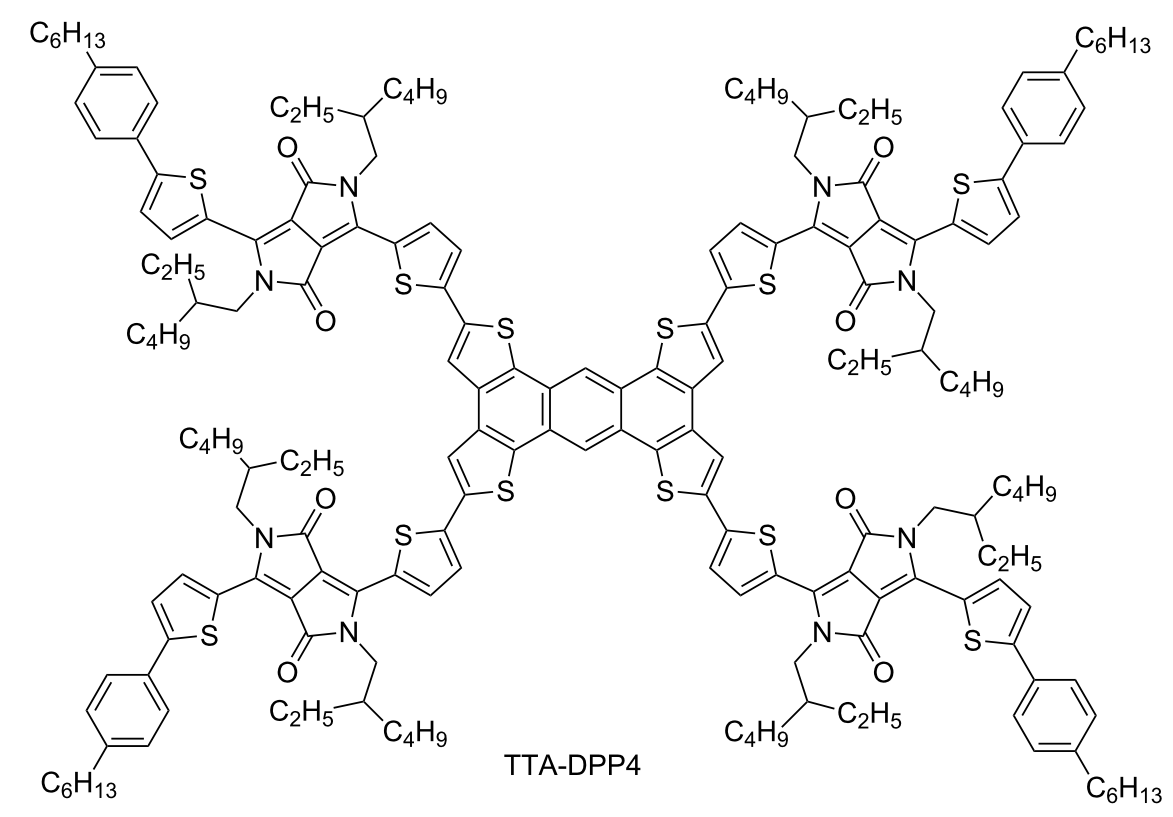

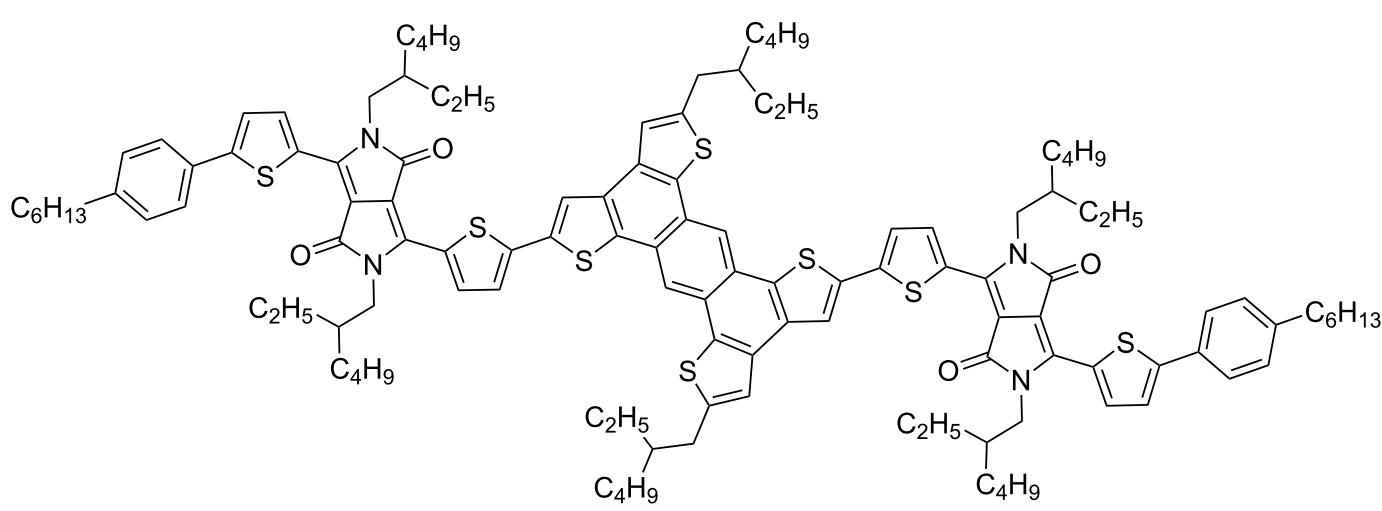

TTA-DPP2 
rendering the molecules with narrower bandgaps, and broad and strong light absorptions. To gain insight into the geometric and electronic structures of TTA-DPP4 and TTA-DPP2, density functional theory (DFT) calculations were performed at the B3LYP/6-31G(d,p) level. The calculated energy levels and the respective frontier orbital distributions for these molecules are displayed in Figure 2. The HOMOs and LUMOs of TTA-DPP4 and TTA-DPP2 are well-expanded across the entire $\pi$-conjugated structure. Both molecules possess similar HOMO and LUMO energy levels of approximately -4.7 and $-2.7 \mathrm{eV}$, respectively. The star-shaped structure has an apparent effect on its oscillator strength $(f)$ such that a larger $f$ value leads to a larger absorption coefficient. Therefore, the four-armed TTADPP4 $(f=3.02)$ is expected to show better photoabsorption ability than the two-armed TTA-DPP2 $(f=2.60)$ because of the two-dimensionally extended $\pi$-conjugated structure.

The synthetic routes to TTA-DPP4 and TTA-DPP2 are outlined in Scheme 1 (see also Experimental section and Supporting Information File 1 for details). TTA-DPP4 and TTA-DPP2 were synthesized in $44 \%$ and $49 \%$ yields, respectively, via the palladium-catalyzed Stille cross-coupling reaction. Both TTADPP4 and TTA-DPP2 were soluble in common organic solvents, such as chloroform, toluene, and chlorobenzene. The thermal stability of these compounds was analyzed by thermo- gravimetric analysis (TGA). As shown in Figure 3, the $5 \%$ weight-loss temperature of TTA-DPP4 and TTA-DPP2, under $\mathrm{N}_{2}$ atmosphere, was determined to be 378 and $380^{\circ} \mathrm{C}$, respectively, suggesting the high thermal stability for these compounds as donor materials.

\section{Optical properties}

The UV-vis absorption spectra of TTA-DPP4 and TTA-DPP2 in chloroform solutions and as-spun thin films are depicted in Figure 4, and the corresponding photophysical data are summarized in Table 1. In chloroform solution, TTA-DPP4 and TTADPP2 exhibit strong and broad absorptions with two characteristic bands: a shorter-wavelength absorption (300-400 nm) arising from $\pi-\pi^{*}$ transitions and a longer-wavelength absorption $(500-700 \mathrm{~nm})$ originating from intramolecular charge transfer (ICT) transitions between the electron-donating TTA and the electron-accepting DPP units. Evidently, the maximum absorption coefficient $(\varepsilon)$ of TTA-DPP4 $\left(22.3 \times 10^{4} \mathrm{M}^{-1} \mathrm{~cm}^{-1}\right)$ is more than twice that of TTA-DPP2 $\left(9.6 \times 10^{4} \mathrm{M}^{-1} \mathrm{~cm}^{-1}\right)$, which is consistent with the increment in the oscillator strength revealed by the DFT calculation results. The ICT absorption peaks are slightly red-shifted and broadened in the solid thin films as compared to those in the chloroform solutions, which can be ascribed to molecular aggregation in the condensed solid state. The optical band gaps of TTA-DPP4 and TTA-DPP2 are
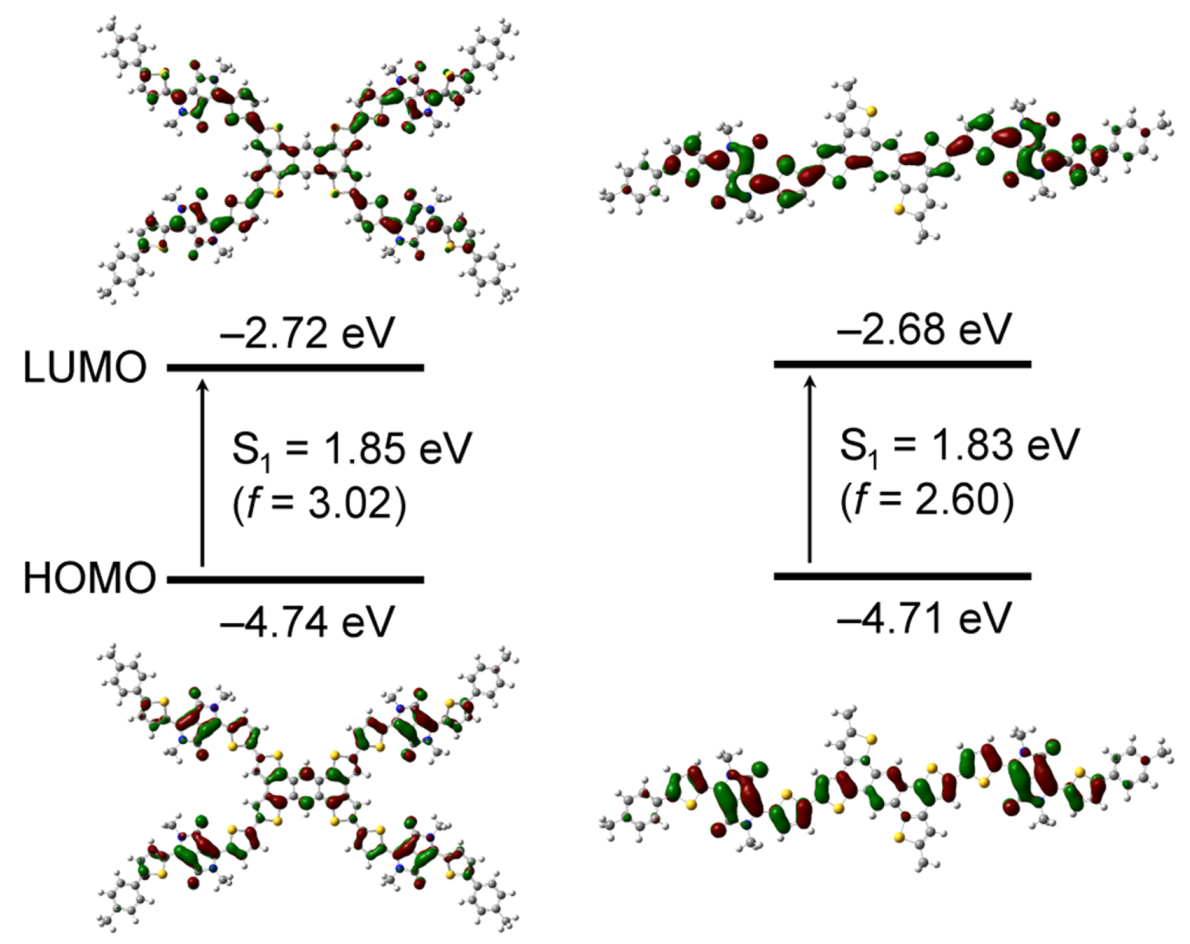

Figure 2: HOMO and LUMO distributions, calculated energy levels, and associated oscillator strengths ( $f$ ) for TTA-DPP4 and TTA-DPP2 calculated at the B3LYP/6-31G $(d, p)$ level. The arrows indicate the first singlet-excited state $\left(S_{1}\right)$ transition. The alkyl chains are modified to methyl groups to simplify the calculations. 


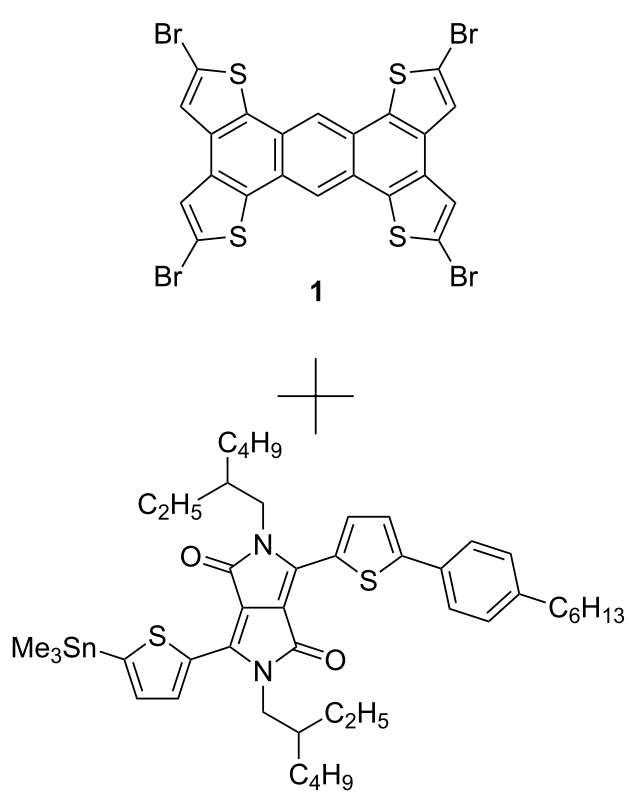

2

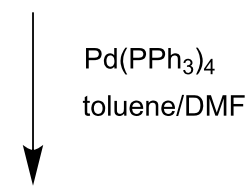

TTA-DPP4

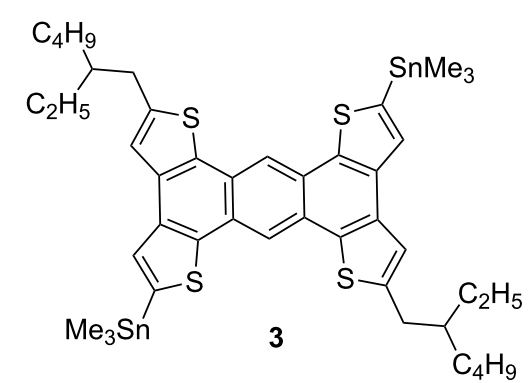

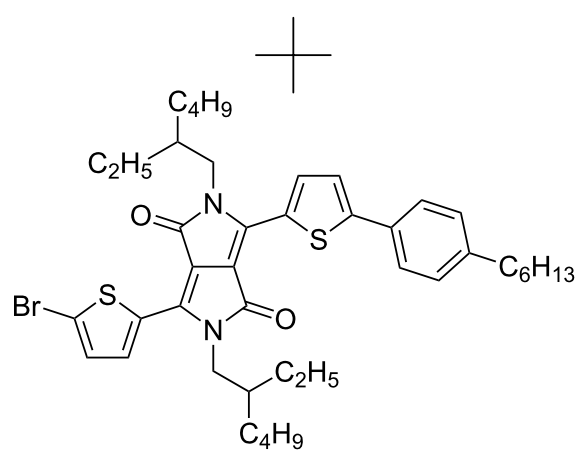

4

$\mathrm{Pd}\left(\mathrm{PPh}_{3}\right)_{4}$ toluene/DMF

TTA-DPP2

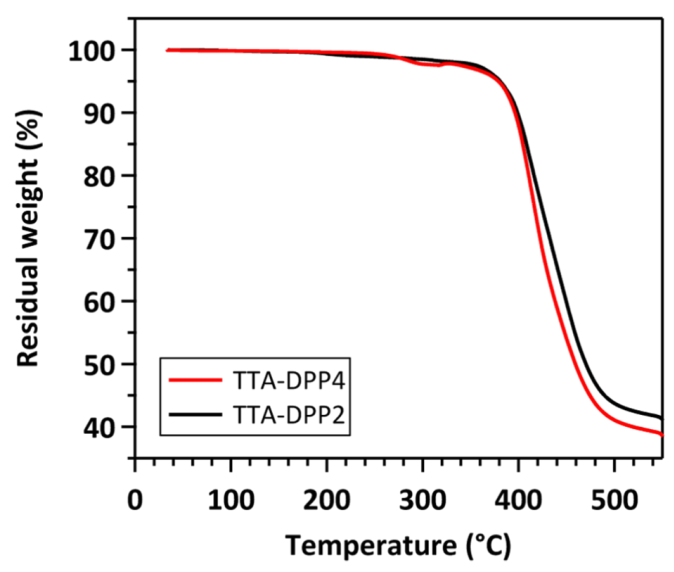

Figure 3: TGA curves of TTA-DPP4 and TTA-DPP2 at a heating rate of $10^{\circ} \mathrm{C} \mathrm{min}-1$ under $\mathrm{N}_{2}$

estimated to be 1.64 and $1.65 \mathrm{eV}$, respectively, from the onset positions of their absorption bands. The absorption coefficient $(\alpha)$ of TTA-DPP4 $\left(16.7 \times 10^{4} \mathrm{~cm}^{-1}\right)$ in the thin film is still considerably larger than that of TTA-DPP2 $\left(11.5 \times 10^{4} \mathrm{~cm}^{-1}\right)$, indicating the enhanced photoabsorption property of the four- armed TTA-DPP4 in the visible region. The HOMO energy levels of TTA-DPP4 and TTA-DPP2 in the thin films were determined to be -5.36 and $-5.40 \mathrm{eV}$, respectively, via photoelectron yield spectroscopy (Figure S1 in Supporting Information File 1). The LUMO energy levels were calculated to be -3.72 and $-3.75 \mathrm{eV}$ for TTA-DPP4 and TTA-DPP2, respectively. Because of their deep-lying HOMO levels and sufficient LUMO offsets $(>0.5 \mathrm{eV})$, both TTA-DPP4 and TTA-DPP2 can serve as electron-donor materials in combination with $[6,6]-$ phenyl- $\mathrm{C}_{71}$-butyric acid methyl ester $\left(\mathrm{PC}_{71} \mathrm{BM}\right)$ as an acceptor materials, which has a LUMO level of $-4.3 \mathrm{eV}$.

\section{Photovoltaic properties}

The photovoltaic properties of TTA-DPP4 and TTA-DPP2 were also evaluated. BHJ-OSCs were fabricated using TTA-DPP4 and TTA-DPP2 as electron-donor materials and $\mathrm{PC}_{71} \mathrm{BM}$ as an electron-acceptor material, with an inverted device configuration of glass/ITO/ZnO/donor: $\mathrm{PC}_{71} \mathrm{BM}(1: 1.5, \mathrm{w} / \mathrm{w}) / \mathrm{MoO}_{3} / \mathrm{Ag}$. A $30 \mathrm{~nm}$ thick $\mathrm{ZnO}$ layer was deposited on the ITO-coated glass via the sol-gel method (see Experimental section). The active layer was then spin-coated from a solution of the donor material and $\mathrm{PC}_{71} \mathrm{BM}$ in a mixed solvent of chloroform/1,8- 

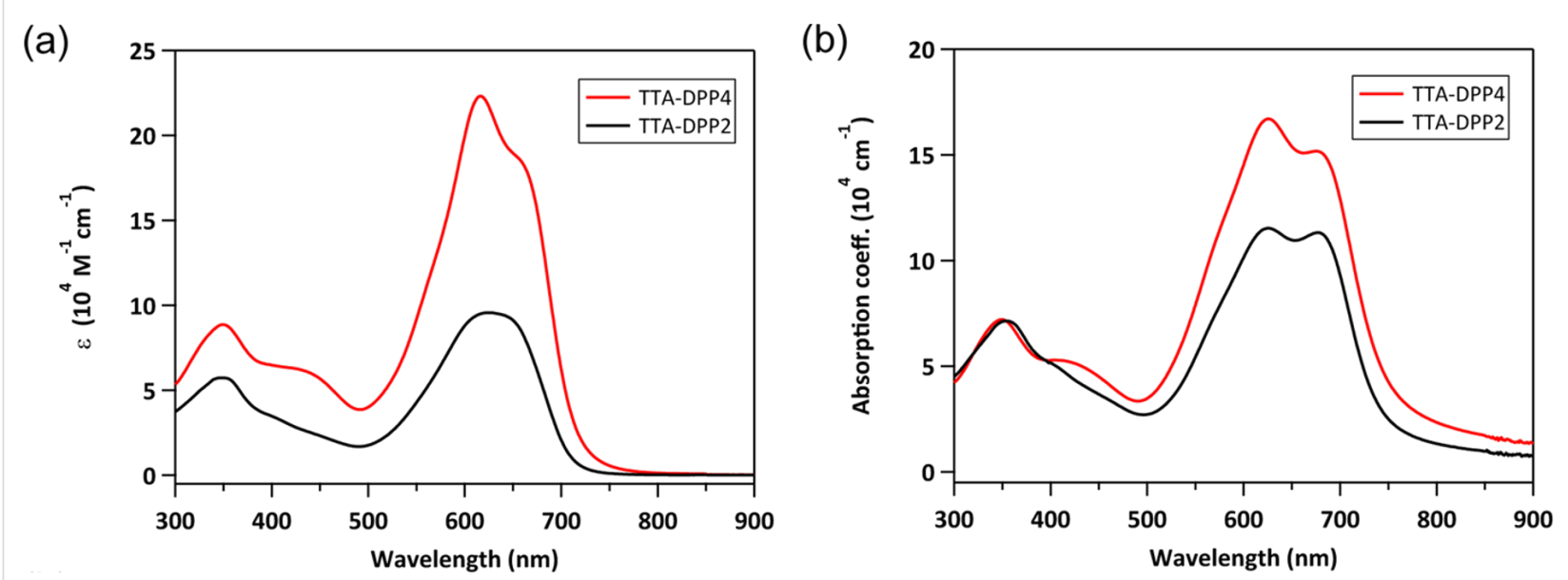

Figure 4: UV-vis absorption spectra of TTA-DPP4 (red) and TTA-DPP2 (black) in (a) chloroform solutions and (b) thin films.

Table 1: Photophysical data of TTA-based molecules.

\begin{tabular}{|c|c|c|c|c|c|c|c|}
\hline & \multicolumn{2}{|c|}{ Solution ${ }^{a}$} & \multicolumn{2}{|c|}{ Thin film ${ }^{b}$} & \multirow[t]{2}{*}{$\mathrm{HOMO}^{\mathrm{c}}[\mathrm{eV}]$} & \multirow[t]{2}{*}{$\mathrm{LUMO}^{\mathrm{d}}[\mathrm{eV}]$} & \multirow[t]{2}{*}{$E_{\mathrm{g}}^{\mathrm{e}}[\mathrm{eV}]$} \\
\hline & $\lambda_{\max }[\mathrm{nm}]$ & $\varepsilon\left[10^{4} \mathrm{M}^{-1} \mathrm{~cm}^{-1}\right]$ & $\lambda_{\max }[\mathrm{nm}]$ & $\alpha\left[10^{4} \mathrm{~cm}^{-1}\right]$ & & & \\
\hline TTA-DPP4 & 616 & 22.3 & 625,676 & 16.7 & -5.36 & -3.72 & 1.64 \\
\hline TTA-DPP2 & 623 & 9.6 & 626,677 & 11.5 & -5.40 & -3.75 & 1.65 \\
\hline
\end{tabular}

${ }^{a}$ Measured in chloroform solutions $\left(10^{-5} \mathrm{M}\right)$; ${ }^{b}$ thin films spin-coated from chloroform solution onto quartz substrate; ${ }^{\mathrm{c}}$ determined by photoelectron yield spectroscopy in spin-coated thin films; ${ }^{d}$ determined from the HOMO and optical energy gap $\left(E_{\mathrm{g}}\right)$ : LUMO $=\mathrm{HOMO}+E_{\mathrm{g}}$; ${ }^{\mathrm{e}}$ derived from the absorption onset of the thin films.

diiodooctane (DIO) $(98: 2, \mathrm{v} / \mathrm{v})$. The thickness of the active layer was controlled within the range of ca. $40-90 \mathrm{~nm}$ by varying the rotation speed during spin-coating. A $6 \mathrm{~nm}$ thick $\mathrm{MoO}_{3}$ layer as a hole extraction layer and a $100 \mathrm{~nm}$ thick $\mathrm{Ag}$ anode were vacuum-deposited on the active layer. The photovoltaic properties of the fabricated BHJ-OSCs were evalu- ated under simulated AM $1.5 \mathrm{G}$ illumination at an intensity of $100 \mathrm{~mW} \mathrm{~cm}^{-2}$ (1 sun).

Figure 5 shows the current density-voltage $(J-V)$ characteristics of the BHJ-OSCs based on TTA-DPP4 and TTA-DPP2 with different active layer thicknesses. The dependence of the (a)

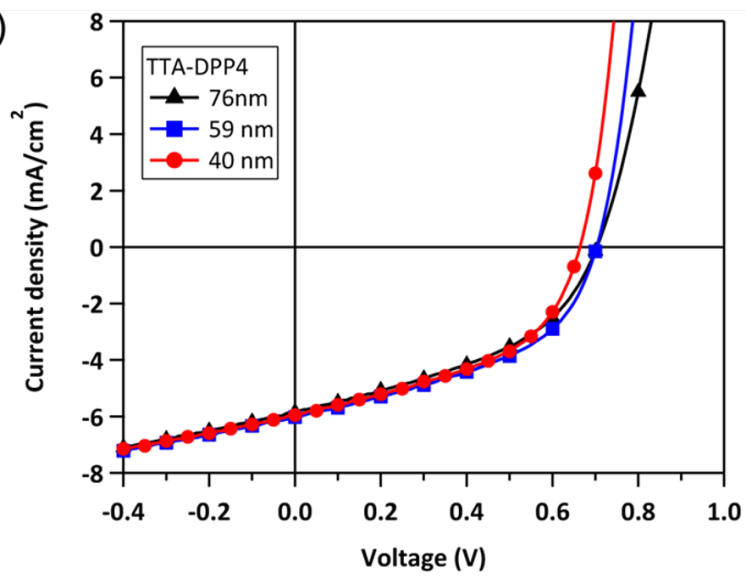

(b)

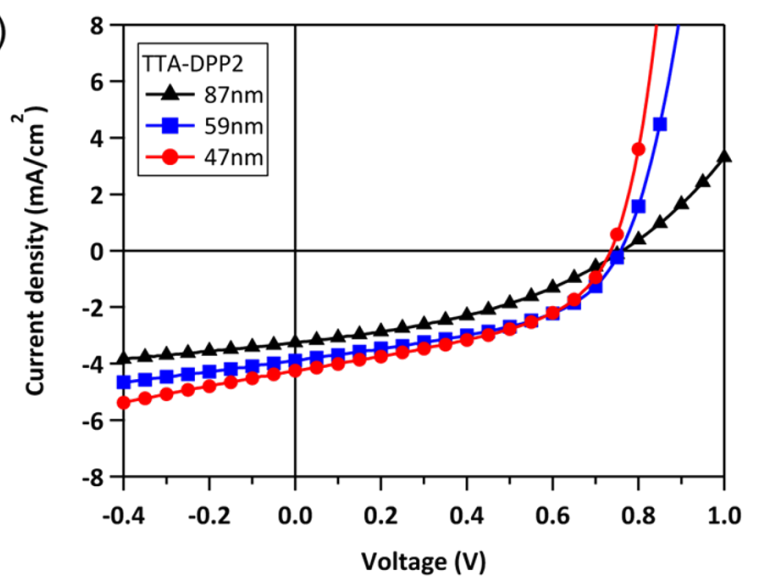

Figure 5: $J-V$ characteristics of BHJ-OSCs based on (a) TTA-DPP4:PC 71 BM (1:1.5, w/w) and (b) TTA-DPP2:PC 71 BM (1:1.5, w/w) with different active layer thicknesses, measured under simulated $A M 1.5 \mathrm{G}, 100 \mathrm{~mW} \mathrm{~cm}^{-1}$ illumination. 
active layer thickness on PCE is presented in Figure 6, and the representative photovoltaic parameters are listed in Table 2. For the TTA-DPP4-based devices, the photovoltaic properties were not influenced much when changing the thickness of the active layer in the range of ca. $40-90 \mathrm{~nm}$, providing PCEs of 1.7-2.0\%. Apparently, the TTA-DPP4-based OSCs showed better photovoltaic performance with a thinner active layer (40-80 nm), as compared to conventional poly(3-hexylthiophene) (P3HT)-based devices. A similar effect of active layer thickness on PCE was also observed in TTA-DPP2-based devices, where a PCE of $1.4 \%$ was obtained with an active layer thickness of $47 \mathrm{~nm}$. In contrast, as presented in Figure 6 and Table 2, the PCEs of P3HT-based devices steeply decreased with decreasing active layer thickness in the range of 40-80 nm, agreeing with the previously reported results [32]. For most of the donor materials, including polymers and small molecules re-

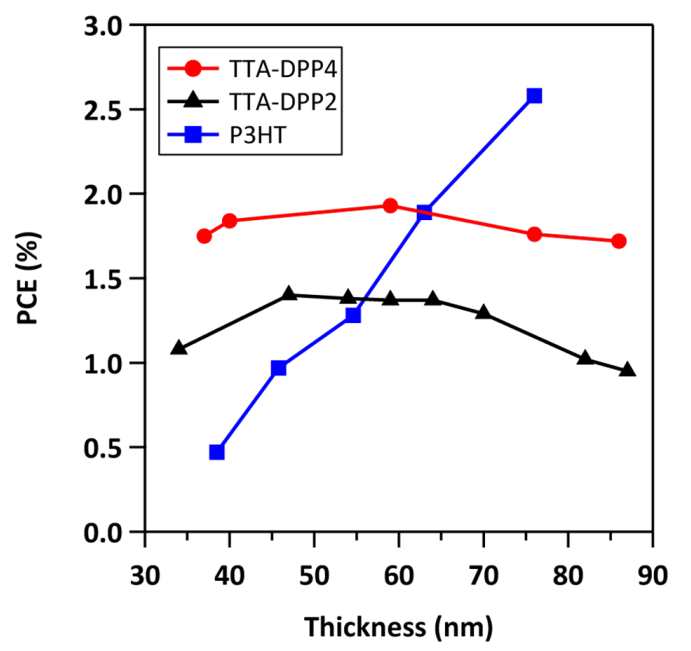

Figure 6: Relationship between active layer thickness and power conversion efficiency (PCE) for TTA-DPP4, TTA-DPP2, and P3HTbased BHJ-OSCs (see also Figures S2-S4 in the Supporting Information File 1 for detailed photovoltaic data). ported, the best photovoltaic performances were generally achieved with an active layer thickness of around $100 \mathrm{~nm}$. However, TTA-DPP4 and TTA-DPP2 presented the highest PCEs with much thinner active layers of approximately 40-60 nm. Moreover, the PCEs of TTA-DPP4-based devices were higher than those of TTA-DPP2, presumably because of its larger absorption coefficient resulting from its star-shaped molecular structure with a two-dimensionally expanded $\pi$-conjugated backbone.

\section{Conclusion}

In this study, the first attempt to introduce a TTA unit as central electron-donating core into star-shaped and linear $\pi$-conjugated oligomers was demonstrated. Multiple electron-accepting DPP arms were attached to the electron-donating TTA core to form star-shaped TTA-DPP4 and linear TTA-DPP2 that have acceptor-donor-acceptor electronic structures. TTA-DPP4 showed a better photoabsorption property than TTA-DPP2 because of its larger oscillator strength, as expected from the DFT calculations. The BHJ-OSCs based on TTA-DPP4 and TTA-DPP2 showed good photovoltaic properties even with thin active layers of 40-60 $\mathrm{nm}$. This behavior was highly different from that of the reported general polymer- and small-moleculebased OSCs. A star-shaped molecular structure containing a two-dimensionally extended $\pi$-conjugated system is a promising electronic system for designing photovoltaic organic materials, as a result of its excellent photoabsorption properties.

\section{Experimental General methods}

Matrix-assisted laser desorption ionization time-of-flight (MALDI-TOF) mass spectra were collected on a Bruker Daltonics Autoflex III spectrometer using dithranol as the matrix. Elemental analysis was carried out using a YANACO CHN coder MT-6. Thermogravimetric analysis (TGA) was performed using a Hitachi High-Tech Science TG/DTA7300 with a

\begin{tabular}{|c|c|c|c|c|c|}
\hline Donor & Thickness [nm] & $J_{\mathrm{SC}}\left[\mathrm{mA} / \mathrm{cm}^{2}\right]$ & $V_{\mathrm{OC}}[\mathrm{V}]$ & FF [\%] & PCE [\%] \\
\hline TTA-DPP4 & $76 \pm 3$ & 5.84 & 0.70 & 42.9 & 1.76 \\
\hline TTA-DPP4 & $59 \pm 1$ & 6.02 & 0.70 & 45.6 & 1.93 \\
\hline TTA-DPP4 & $40 \pm 2$ & 5.95 & 0.66 & 46.7 & 1.84 \\
\hline TTA-DPP2 & $87 \pm 1$ & 3.26 & 0.76 & 44.9 & 0.95 \\
\hline TTA-DPP2 & $59 \pm 1$ & 3.89 & 0.76 & 46.4 & 1.37 \\
\hline TTA-DPP2 & $47 \pm 2$ & 4.25 & 0.74 & 44.7 & 1.40 \\
\hline P3HT & $76 \pm 1$ & 7.32 & 0.56 & 62.8 & 2.58 \\
\hline P3HT & $55 \pm 1$ & 5.60 & 0.43 & 52.4 & 1.28 \\
\hline Р3HT & $39 \pm 1$ & 2.97 & 0.32 & 50.0 & 0.47 \\
\hline
\end{tabular}


heating rate of $10{ }^{\circ} \mathrm{C} \mathrm{min}^{-1}$ under $\mathrm{N}_{2}$ atmosphere. UV-vis absorption spectra were recorded on a JASCO V-670Y spectrometer. Photoelectron yield spectra were recorded on a RikenKeiki AC-2 ultraviolet photoelectron spectrometer. The thickness of photoactive layers was measured using a Bruker DektakXT system.

\section{Synthesis}

All reactions were carried out under $\mathrm{N}_{2}$ atmosphere using standard Schlenk techniques. All starting materials, unless otherwise specified, were purchased from commercial suppliers and used without further purification. 2,5,9,12-Tetrabromoanthra[1,2-b:4,3- $\left.b^{\prime}: 5,6-b^{\prime \prime}: 8,7-b^{\prime \prime \prime}\right]$ tetrathiophene (1) [25], 2,5-bis(2ethylhexyl)-3-(5-(4-hexylphenyl)thiophen-2-yl)-6-(5-(trimethylstannyl)thiophen-2-yl)-2,5-dihydropyrrolo[3,4-c]pyrrole-1,4dione (2) [30,33], (5,12-bis(2-ethylhexyl)anthra[1,2-b:4,3$\left.b^{\prime}: 5,6-b ": 8,7-b^{\prime \prime}\right]$ tetrathiophene-2,9-diyl)bis(trimethylstannane) (3) $[24,27]$, and 3-(5-bromothiophen-2-yl)-2,5-bis(2ethylhexyl)-6-(5-(4-hexylphenyl)thiophen-2-yl)-2,5-dihydropyrrolo[3,4-c]pyrrole-1,4-dione (4) [30] were synthesized according to the reported procedures. Detailed synthetic schemes for these compounds are provided in the Supporting Information File 1.

Synthesis of TTA-DPP4: To a mixture of 1 (0.19 g, $0.27 \mathrm{mmol})$ and $2(2.29 \mathrm{~g}, 2.70 \mathrm{mmol})$ in a mixture of dry DMF $(10 \mathrm{~mL})$ and dry toluene $(20 \mathrm{~mL})$ was added $\mathrm{Pd}\left(\mathrm{PPh}_{3}\right)_{4}$ $(0.016 \mathrm{~g}, 0.014 \mathrm{mmol})$. The mixture was stirred for $38 \mathrm{~h}$ at $120{ }^{\circ} \mathrm{C}$. After cooling to room temperature, the reaction mixture was poured into water and then extracted with chloroform. The combined organic layers were washed with water and dried over anhydrous $\mathrm{Na}_{2} \mathrm{SO}_{4}$. After filtration and evaporation, the product was purified by silica gel column chromatography (eluent: chloroform/hexane 4:1, v/v) to provide TTA-DPP4 as a dark purple solid. This compound was further purified by recycling preparative gel permeation chromatography (GPC; eluent: chloroform) prior to use (yield $=0.36 \mathrm{~g}, 44 \%$ ). MS (MALDI-TOF) $\mathrm{m} / \mathrm{z}$ : $[\mathrm{M}]^{+}$calcd for 3133.42 ; found 3133.51 ; anal. calcd (\%) for $\mathrm{C}_{190} \mathrm{H}_{226} \mathrm{~N}_{8} \mathrm{O}_{8} \mathrm{~S}_{12}: \mathrm{C}, 72.80 ; \mathrm{H}, 7.27 ; \mathrm{N}$, 3.57; found: C, 71.29; H, 7.15; N, 3.53. Well-resolved NMR signals could not be obtained for both TTA-DPP4 and TTADPP2 in $\mathrm{CDCl}_{3}$ or DMSO- $d_{6}$ even at elevated temperatures due to the macromolecular nature of the compounds (Figure S5 in Supporting Information File 1). The experimental results of isotope pattern deconvolution in mass spectra of TTA-DPP4 and TTA-DPP2 showed good agreements with the theoretical isotope patterns, supporting their chemical structures.

Synthesis of TTA-DPP2: This compound was prepared in a similar fashion to TTA-DPP4, using $3(0.31 \mathrm{~g}, 0.33 \mathrm{mmol})$ and $4(0.53 \mathrm{~g}, 0.69 \mathrm{mmol})$, and $\mathrm{Pd}\left(\mathrm{PPh}_{3}\right)_{4}(0.015 \mathrm{~g}, 0.013 \mathrm{mmol})$.
The product was purified by silica gel column chromatography (eluent: chloroform/hexane 1:1, v/v) and GPC to give TTADPP2 as a dark purple solid (yield $=0.32 \mathrm{~g}, 49 \%$ ). MS (MALDI-TOF) $\mathrm{m} / \mathrm{z}$ : $[\mathrm{M}]^{+}$calcd for 1991.95; found 1991.67; anal. calcd (\%) for $\mathrm{C}_{122} \mathrm{H}_{150} \mathrm{~N}_{4} \mathrm{O}_{4} \mathrm{~S}_{8}: \mathrm{C}, 73.52 ; \mathrm{H}, 7.59 ; \mathrm{N}$, 2.81; found: C, 73.33; H, 7.53; N, 2.84 .

\section{Fabrication and evaluation of organic solar cells}

The OSC devices were fabricated and tested by using similar procedures described in reference [30]. Pre-patterned ITOcoated glass substrates were cleansed sequentially by sonicating in detergent solution, deionized water, acetone, and isopropanol for $15 \mathrm{~min}$ each, and then subjected to UV/ozone treatment for $30 \mathrm{~min}$. A thin layer $(\sim 30 \mathrm{~nm})$ of $\mathrm{ZnO}$ was prepared by spin-coating (at $5000 \mathrm{rpm}$ ) a precursor solution of zinc acetate $(0.50 \mathrm{~g})$ and ethanolamine $(0.14 \mathrm{~g})$ in 2-methoxyethanol $(5 \mathrm{~mL})$, followed by baking at $200{ }^{\circ} \mathrm{C}$ for $10 \mathrm{~min}$ under air. The photoactive layer was then prepared by spin-coating from a chloroform solution containing the donor material and $\mathrm{PC}_{71} \mathrm{BM}$, after passing through a $0.45 \mu \mathrm{m}$ PTFE membrane filter. Finally, a $6 \mathrm{~nm}$ thick $\mathrm{MoO}_{3}$ layer and a $100 \mathrm{~nm}$-thick $\mathrm{Ag}$ layer were thermally evaporated on top of the active layer under high vacuum through a shadow mask, defining an active area of $0.04 \mathrm{~cm}^{2}$ for each device. Current density-voltage $(J-V)$ measurements for the fabricated OSCs were conducted on a computer-controlled Keithley 2400 source measure unit in air, under simulated AM 1.5G solar illumination at $100 \mathrm{~mW} \mathrm{~cm}^{-2}$ (1 sun), using a Xe lamp-based Bunko-Keiki SRO-25 GD solar simulator. The light intensity was calibrated using a standard silicon photovoltaic reference cell.

\section{Supporting Information}

\section{Supporting Information File 1}

Synthesis of compounds 1-13, evaluation of HOMO levels for TTA-DPP4 and TTA-DPP2, photovoltaic properties of TTA-DPP4, TTA-DPP2, and P3HT-based OSCs and ${ }^{1} \mathrm{H}$ NMR spectra of TTA-DPP4 and TTA-DPP2. [http://www.beilstein-journals.org/bjoc/content/ supplementary/1860-5397-12-142-S1.pdf]

\section{Acknowledgements}

This work was partially supported by the ACCEL project from Japan Science and Technology Agency (JST), and Grants-inAid for Scientific Research (Nos. 16K21218 (H.K.) and 15 H01049 (T.Y.)) from JSPS, the Cooperative Research Program of "Network Joint Research Center for Materials and Devices", the Yoshida Education and Foundation (H.K.), the Yashima Environment Technology Foundation (T.Y.), and the 
KDDI Foundation Research Grant (T.Y.). H.K. and C.A. acknowledge the support of WPI-I2CNER, sponsored by MEXT, Japan.

\section{References}

1. Yu, G.; Gao, J.; Hummelen, J. C.; Wudi, F.; Heeger, A. J. Science 1995, 270, 1789-1791. doi:10.1126/science.270.5243.1789

2. Li, G.; Shrotriya, V.; Huang, J.; Yao, Y.; Moriarty, T.; Emery, K.; Yang, Y. Nat. Mater. 2005, 4, 864-868. doi:10.1038/nmat1500

3. Sun, Y.; Welch, G. C.; Leong, W. L.; Takacs, C. J.; Bazan, G. C.; Heeger, A. J. Nat. Mater. 2012, 11, 44-48. doi:10.1038/nmat3160

4. Zhang, Q.; Kan, B.; Liu, F.; Long, G.; Wan, X.; Chen, X.; Zuo, Y.; Ni, W.; Zhang, H.; Li, M.; Hu, Z.; Huang, F.; Cao, Y.; Liang, Z.; Zhang, M.; Russell, T. P.; Chen, Y. Nat. Photonics 2015, 9, 35-41. doi:10.1038/nphoton.2014.269

5. Kan, B.; Li, M.; Zhang, Q.; Liu, F.; Wan, X.; Wang, Y.; Ni, W.; Long, G.; Yang, X.; Feng, H.; Zuo, Y.; Zhang, M.; Huang, F.; Cao, Y.; Russell, T. P.; Chen, Y. J. Am. Chem. Soc. 2015, 137, 3886-3893. doi:10.1021/jacs.5b00305

6. Liu, C.; Yi, C.; Wang, K.; Yang, Y.; Bhatta, R. S.; Tsige, M.; Xiao, S.; Gong, X. ACS Appl. Mater. Interfaces 2015, 7, 4928-4935. doi:10.1021/am509047g

7. Vohra, V.; Kawashima, K.; Kakara, T.; Koganezawa, T.; Osaka, I.; Takimiya, K.; Murata, H. Nat. Photonics 2015, 9, 403-408. doi:10.1038/nphoton.2015.84

8. Schmidt-Mende, L.; Fechtenkötter, A.; Müllen, K.; Moons, E.; Friend, R. H.; MacKenzie, J. D. Science 2001, 293, 1119-1122. doi:10.1126/science.293.5532.1119

9. Wong, W. W. H.; Jones, D. J.; Yan, C.; Watkins, S. E.; King, S.; Haque, S. A.; Wen, X.; Ghiggino, K. P.; Holmes, A. B. Org. Lett. 2009, 11, 975-978. doi:10.1021/ol8029164

10. Wong, W. W. H.; Khoury, T.; Vak, D.; Yan, C.; Jones, D. J.; Crossley, M. J.; Holmes, A. B. J. Mater. Chem. 2010, 20, 7005-7014. doi:10.1039/c0jm00311e

11. Wong, W. W. H.; Ma, C.-Q.; Pisula, W.; Yan, C.; Feng, X.; Jones, D. J.; Müllen, K.; Janssen, R. A. J.; Bäuerle, P.; Holmes, A. B. Chem. Mater. 2010, 22, 457-466. doi:10.1021/cm903272y

12. Ren, S.; Yan, C.; Vak, D.; Jones, D. J.; Holmes, A. B.; Wong, W. W. H. Adv. Funct. Mater. 2012, 22, 2015-2026. doi:10.1002/adfm.201102141

13. Wong, W. W. H.; Subbiah, J.; Puniredd, S. R.; Purushothaman, B.; Pisula, W.; Kirby, N.; Müllen, K.; Jones, D. J.; Holmes, A. B. J. Mater. Chem. 2012, 22, 21131-21137. doi:10.1039/c2jm34394k

14. Hu, N.; Shao, R.; Shen, Y.; Chen, D.; Clark, N. A.; Walba, D. M. Adv. Mater. 2014, 26, 2066-2071. doi:10.1002/adma.201304371

15. Takemoto, K.; Karasawa, M.; Kimura, M. ACS Appl. Mater. Interfaces 2012, 4, 6289-6294. doi:10.1021/am301905m

16. Liu, S.-Y.; Liu, W.-Q.; Xu, J.-Q.; Fan, C.-C.; Fu, W.-F.; Ling, J.; Wu, J.-Y.; Shi, M.-M.; Jen, A. K.-Y.; Chen, H.-Z. ACS Appl. Mater. Interfaces 2014, 6, 6765-6775. doi:10.1021/am500522x

17. Takemoto, K.; Kimura, M. RSC Adv. 2014, 4, 64589-64595. doi:10.1039/C4RA10347E

18. Roquet, S.; Cravino, A.; Leriche, P.; Alévêque, O.; Frère, P.; Roncali, J. J. Am. Chem. Soc. 2006, 128, 3459-3466. doi:10.1021/ja058178e

19. Zhang, J.; Deng, D.; He, C.; He, Y.; Zhang, M.; Zhang, Z.-G.; Zhang, Z.; Li, Y. Chem. Mater. 2011, 23, 817-822. doi:10.1021/cm102077j

20. Lin, Y.; Zhang, Z.-G.; Li, Y.; Zhu, D.; Zhan, X. J. Mater. Chem. A 2013, 1, 5128-5135. doi:10.1039/c3ta10205j
21. Paek, S.; Cho, N.; Cho, S.; Lee, J. K.; Ko, J. Org. Lett. 2012, 14, 6326-6329. doi:10.1021/ol303045p

22. Paek, S.; Choi, H.; Sim, J.; Song, K.; Lee, J. K.; Ko, J. J. Phys. Chem. C 2014, 118, 27193-27200. doi:10.1021/jp5071709

23. Shang, H.; Fan, H.; Liu, Y.; Hu, W.; Li, Y.; Zhan, X. Adv. Mater. 2011, 23, 1554-1557. doi:10.1002/adma.201004445

24. He, F.; Wang, W.; Chen, W.; Xu, T.; Darling, S. B.; Strzalka, J.; Liu, Y.; Yu, L. J. Am. Chem. Soc. 2011, 133, 3284-3287. doi:10.1021/ja1110915

25. Brusso, J. L.; Hirst, O. D.; Dadvand, A.; Ganesan, S.; Cicoira, F.; Robertson, C. M.; Oakley, R. T.; Rosei, F.; Perepichka, D. F. Chem. Mater. 2008, 20, 2484-2494. doi:10.1021/cm7030653

26. Leitch, A. A.; Stobo, K. A.; Hussain, B.; Ghoussoub, M.; Ebrahimi-Takalloo, S.; Servati, P.; Korobkov, I.; Brusso, J. L. Eur. J. Org. Chem. 2013, 26, 5854-5863. doi:10.1002/ejoc.201300731

27. Li, C.; Zheng, N.; Chen, H.; Huang, J.; Mao, Z.; Zheng, L.; Weng, C.; Tan, S.; Yu, G. Polym. Chem. 2015, 6, 5393-5404. doi:10.1039/C5PY00605H

28. Wienk, M. M.; Turbiez, M.; Gilot, J.; Janssen, R. A. J. Adv. Mater. 2008, 20, 2556-2560. doi:10.1002/adma.200800456

29. Shin, W.; Yasuda, T.; Watanabe, G.; Yang, Y. S.; Adachi, C. Chem. Mater. 2013, 25, 2549-2556. doi:10.1021/cm401244x

30. Shin, W.; Yasuda, T.; Hidaka, Y.; Watanabe, G.; Arai, R.; Nasu, K.; Yamaguchi, T.; Murakami, W.; Makita, K.; Adachi, C. Adv. Energy Mater. 2014, 4, 1400879. doi:10.1002/aenm.201400879

31. Huang, J.; Zhan, C.; Zhang, X.; Zhao, Y.; Lu, Z.; Jia, H.; Jiang, B.; Ye, J.; Zhang, S.; Tang, A.; Liu, Y.; Pei, Q.; Yao, J. ACS Appl. Mater. Interfaces 2013, 5, 2033-2039. doi:10.1021/am302896u

32. Dang, M. T.; Hirsch, L.; Wantz, G. Adv. Mater. 2011, 23, 3597-3602. doi:10.1002/adma.201100792

33. Fu, L.; Fu, W.; Cheng, P.; Xie, Z.; Fan, C.; Sh, M.; Ling, J.; Hou, J.; Zhanc, X.; Chen, H. J. Mater. Chem. A 2014, 2, 6589-6597. doi:10.1039/c3ta13534a

\section{License and Terms}

This is an Open Access article under the terms of the Creative Commons Attribution License (http://creativecommons.org/licenses/by/2.0), which permits unrestricted use, distribution, and reproduction in any medium, provided the original work is properly cited.

The license is subject to the Beilstein Journal of Organic Chemistry terms and conditions:

(http://www.beilstein-journals.org/bjoc)

The definitive version of this article is the electronic one which can be found at:

$\underline{\text { doi: } 10.3762 / \text { bjoc. } 12.142}$ 